\title{
Beta-3 Adrenoceptor Signaling Pathways in Urothelial and Smooth Muscle Cells in the Presence of Succinate
}

\author{
(D)Abubakr Mossa, @ Monica Velasquez Flores, Hieu Nguyen, Philippe G. Cammisotto, \\ and (1)Lysanne Campeau
}

Lady Davis Research Institute, McGill University, Montreal, Quebec, Canada

Received April 19, 2018; accepted August 8, 2018

\begin{abstract}
Succinate, an intermediate metabolite of the Krebs cycle, can alter the metabolomics response to certain drugs and controls an array of molecular responses in the urothelium through activation of its receptor, G-protein coupled receptor 91 (GPR91). Mirabegron, a $\beta 3$-adrenergic receptor ( $\beta 3$-AR) agonist used to treat overactive bladder syndrome (OAB), increases intracellular cAMP in the detrusor smooth muscle cells (SMC), leading to relaxation. We have previously shown that succinate inhibits forskolin-stimulated cAMP production in urothelium. To determine whether succinate interferes with mirabegron-mediated bladder relaxation, we examined their individual and synergistic effect in urothelial-cell and SMC signaling. We first confirmed $\beta 3-A R$ involvement in the mirabegron response by quantifying receptor abundance by immunoblotting in cultured urothelial cells and SMC and cellular localization by immunohistochemistry in
\end{abstract}

rat bladder tissue. Mirabegron increased cAMP levels in SMC but not in urothelial cells, an increase that was inhibited by succinate, suggesting that it impairs cAMP-mediated bladder relaxation by mirabegron. Succinate and mirabegron increased inducible nitric oxide synthesis and nitric oxide secretion only in urothelial cells, suggesting that its release can indirectly induces SMC relaxation. Succinate exposure decreased the expression of $\beta 3-A R$ protein in whole bladder in vivo and in SMC in vitro, indicating that this metabolite may lead to impaired pharmacodynamics of the bladder. Together, our results demonstrate that increased levels of succinate in settings of metabolic stress (e.g., the metabolic syndrome) may lead to impaired mirabegron and $\beta 3-A R$ interaction, inhibition of cAMP production, and ultimately requiring mirabegron dose adjustment for its treatment of $\mathrm{OAB}$ related to these conditions.

\section{Introduction}

A growing body of evidence has demonstrated the impact of body metabolites on drug efficacy and standard therapeutic responses. Pharmacometabolomic studies, as one of their main objectives, have linked the pretreatment level of body metabolites with the patient response to treatments such as neuropsychiatric, anticancer, and cardiovascular drugs (Sun et al., 2013; Kaddurah-Daouk and Weinshilboum, 2015; Kantae et al., 2017). For instance, succinate was found to be one of the metabolites that affect the body's response to certain drugs (Trupp et al., 2012; Sun et al., 2013). Succinate, an intermediate of the citric acid cycle, increases in cases of

This research was supported by a Canadian Urological Association Foundation CUA Astellas Research Grant.

https://doi.org/10.1124/jpet.118.249979. metabolic stress such as hyperglycemia, insulin resistance, hypoxia, and inflammation. Under these circumstances, the inhibition of nuclear transcription factors sirtuins (SIRTs) results in increased production and secretion of succinate and up-regulation in the expression of its receptor, G-protein coupled receptor 91 (GPR91) ( $\mathrm{Li}$ et al., 2016). Binding of succinate to GPR91 triggers intracellular signaling pathways involving extracellular signal-regulated kinase (ERK), c-Jun $\mathrm{N}$-terminal kinase (JNK), and mitogen-activated protein kinase (MAPK), changes in intracellular calcium levels, and secretion of nitric oxide (NO) in different cell types (He et al., 2004; Vargas et al., 2009; Mossa et al., 2017).

States of energy metabolism disruption (e.g., obesity, diabetes, and insulin resistance), hypoxia, or inflammation also potently affect bladder function (Rohrmann et al., 2005; He et al., 2016). Overactive bladder syndrome (OAB) is characterized by urinary urgency, increased urinary frequency, nocturia,

ABBREVIATIONS: $\beta 3$-AR, $\beta 3$-adrenergic receptor; BSA, bovine serum albumin; CGP-20712A, 2-hydroxy-5-[2-[[2-hydroxy-3-[4-[1-methyl-4(trifluoromethyl)imidazol-2-yl]phenoxy]propyl]amino]ethoxy]benzamide; DMEM, Dulbecco's modified Eagle's medium; ERK, extracellular signal-regulated kinase; FBS, fetal bovine serum; GPR91, G-protein coupled receptor 91; HRP, horseradish peroxidase; ICl-118, 551 $(2 R, 3 R)$-1-[(7-methyl-2,3-dihydro-1H-inden-4-yl)oxy]-3-(propan-2-ylamino)butan-2-ol; iNOS, inducible nitric oxide synthase; JNK, c-Jun $\mathrm{N}$-terminal kinase; L-NAME, methyl (2S)-2-amino-5-[[amino(nitramido)methylidene]amino]pentanoate; MAPK, mitogen-activated protein kinase; NO, nitric oxide; OAB, overactive bladder syndrome; PBS, phosphate-buffered saline; PCR, polymerase chain reaction; PD98059, 2-(2-amino-3-methoxyphenyl)chromen-4-one; PTX, pertussis toxin; qRT-PCR, quantitative real-time polymerase chain reaction; RT-PCR, reverse transcription polymerase chain reaction; SD, Sprague-Dawley rats; SMC, smooth muscle cells; TBST, Tris-buffered saline containing $0.1 \%$ Tween-20 (TBST); Y27632, 4-[(1R)-1-aminoethyl]- $N$-pyridin-4-ylcyclohexane-1-carboxamide; UBO, UBO-QIC ([(1R)-1-[(3S,6S,9S,12S,18R,21S,22R)21-acetamino-18-benzyl-3-[(1R)-1-methoxyethyl-2-yl-1,19-dioxa-4,7,10,12,16-pentazacyclodocos-6-yl]-2-methylpropyl](2S,3R)-3-hydroxy-4methyl-2-(propanoylamino)pentanoate). 
with or without urinary incontinence (Abrams, 2003). This pathology affects both men and women, increases with age, and results in significant loss of quality of life. Treatments first focus on behavioral and lifestyle changes combined or followed by drug therapy (Gormley et al., 2015; Corcos et al., 2017). Antimuscarinic agents have been prescribed, but the multiple side effects (e.g., xerostomia, constipation) lead to poor adherence (Abrams and Andersson, 2007).

Mirabegron, a $\beta 3$-adrenergic receptor $(\beta 3-\mathrm{AR})$ agonist used in the treatment of $\mathrm{OAB}$, has the advantage of being well tolerated with a different side effect profile. Administration of mirabegron indeed leads to bladder relaxation, in vivo and in vitro, both in humans and rodents (Yamaguchi and Chapple, 2007; Nitti et al., 2013; Sadananda et al., 2013). The mechanism of the relaxing effect with mirabegron is thought to mainly involve the binding of mirabegron to its receptor located on smooth muscle cells (SMC) of the detrusor, increasing cAMP production, decreasing intracellular calcium levels, and ultimately decreasing bladder contractions during the filling phase. This results in a reduction of urgency and incontinence episodes and a decreased frequency of micturition (Yamaguchi and Chapple, 2007).

We previously demonstrated that the succinate receptor GPR91 is expressed by urothelial cells and the SMC of the bladder in rodents (Mossa et al., 2017). GPR91 and $\beta 3$-AR share common pathways (Mossa et al., 2017). Taking into account the central role of succinate in several pathologies affecting bladder function and the scarcity of data on its role in bladder physiology, we have assessed how succinate might impact the $\beta 3$-AR activity of SMC and urothelial cells.

\section{Materials and Methods}

Cell Culture. Female Sprague-Dawley (SD) rats aged 3 months were housed and handled in accordance with the Canadian Council for Animal Care (CCAC). All protocols were approved by the Animal Ethics Committee of McGill University (Montreal, Canada). The animals received standard Purina chow and had free access to water. Cells were isolated from bladder using collagenase type IV digestion. After euthanasia by exsanguination under anesthesia was performed, the bladder was excised and quickly placed in cold sterile phosphate-buffered saline (PBS) ( $\mathrm{pH} 7.4$ ), cut longitudinally, and spread; the urothelium was carefully scraped and placed in Dulbecco's modified Eagle's medium (DMEM) medium containing $100 \mathrm{U} / \mathrm{ml}$ of collagenase IV for 15-20 minutes with gentle shaking.

Urothelial cells were washed twice in DMEM $10 \%$ fetal bovine serum (FBS) then placed in a Dulbecco's DMEM low glucose/keratinocyte (50/50) medium containing FBS (10\%), GlutaMAX (X1), a hormone mix (insulin $5 \mu \mathrm{g} / \mathrm{ml}$, dihydrocortisone $0.5 \mu \mathrm{g} / \mathrm{ml}$, adenine $15 \mu \mathrm{g} / \mathrm{ml}$, ethanolamine $0.1 \mathrm{mM})$, Rho inhibitor 4-[(1R)-1-aminoethyl]- $N$-pyridin4-ylcyclohexane-1-carboxamide (Y27632) $(10 \mu \mathrm{M})$, and 1\% penicillin/ streptomycin $(100 \mathrm{U} / \mathrm{ml}, 100 \mu \mathrm{g} / \mathrm{ml})$ in a humidified incubator with $5 \% \mathrm{CO}_{2}$ atmosphere. The medium was replaced every 2 to 3 days until cell confluency. Cells were starved 24 hours before use.

In parallel, detrusor muscle was finely minced and incubated for 45 minutes in DMEM containing $250 \mathrm{U} / \mathrm{ml}$ of collagenase IV, with intense shaking, then placed on a strainer ( $40 \mu \mathrm{m}$ mesh) to retain undigested materials. After two washings with DMEM/FBS, the SMC were seeded on a Petri dish in DMEM medium supplemented with FBS (10\%), GlutaMAX (1\%), high glucose (27 mM), and penicillin/ streptomycin $(100 \mathrm{U} / \mathrm{ml}, 100 \mu \mathrm{g} / \mathrm{ml})$. The incubation conditions were similar to those of urothelial cells. Before use, the cells were starved for 72 hours in a normoglycemic medium. Incubation with succinate at $[200 \mu \mathrm{M}]$ was based on our previous study to activate GPR91 receptor and mimic the pathophysiologic concentrations of succinate (Mossa et al., 2017).

Reagents and Antibodies. Mirabegron was dissolved in dimethylsulfoxide and diluted in phosphate-buffered saline (PBS) to the final concentration in the culture medium. Cell responses to mirabegron were performed at $[10 \mu \mathrm{M}]$ based on the dose-response curve to obtain $\approx 75 \%$ response (Fig. $2 \mathrm{D}$ ). Chemicals and antibodies were purchased as follows: Mirabegron from Toronto Research Chemical (Toronto, CA); forskolin and the cAMP enzyme-linked immunosorbent assay kit from Cayman Chemical (Ann Arbor, MI); P-JNK and JNK antibodies from ThermoFisher Scientific (Waltham, MA); $\beta$-actin antibody from ProteinTech (Rosemont, IL); phosphoERK and total ERK antibodies from R\&D Systems (Minneapolis, $\mathrm{MN}$ ); inducible nitric oxide synthase (iNOS) and $\beta 3-\mathrm{AR}$ antibody from NovusBio (Oakville, ON, Canada); fetal bovine serum (FBS) from Wisent (Quebec, Canada); penicillin/streptomycin from VWR International (Quebec, Canada); the BCA protein assay kit from Boster Biological Technology (Pleasanton, CA); collagenase type IV from Worthington Biochemical (Lakewood, NJ); DMEM and MCD153 media from US Biologic Life Science (Salem, MA); GlutaMAX and keratinocyte medium supplemented with epidermal growth factor and bovine pituitary extract from Gibco/ThermoFisher Scientific (Grand Island, NY); ATP, D-glucose, ethanolamine, bovine serum albumin (BSA), and succinate from Sigma-Aldrich (Oakville, ON, Canada); adenine from Biomatik (Cambridge, ON, Canada); dihydrocortisone from MP Biochemicals (Solon, OH); and Y27632 from Selleckchem, Houston, TX). UBO was a generous gift from Dr. T. Hebert (McGill University, Montreal).

Bladder Tissue. Bladder specimens for immunohistochemistry, immunoblotting, and polymerase chain reaction (PCR) were collected from male SD rats purchased from Charles River (Montreal, QC, Canada). The protocol was approved by the animal ethics committee of McGill University (Montreal, Canada). The rats had free access to food (standard Purina chow) and water and were kept on a 12-hour light/dark cycle. Intraperitoneal injections of succinate $\left(50 \mathrm{mg} / \mathrm{kg}^{-1}\right)$ or saline (control) were performed daily (morning) for 4 weeks.

Immunohistochemistry. Bladder pieces were fixed in paraformaldehyde $4 \%$ in PBS and processed for paraffin embedding. After rehydration, the slides were heated for 20 minutes in citrate buffer (10 mM, pH 6.0) at $95^{\circ} \mathrm{C}$. Tissue sections were blocked with (0.6\% BSA in PBS, $0.3 \%$ Triton, $10 \%$ goat serum) for 30 minutes, then placed with the primary antibody anti- $\beta 3$-AR (diluted 1:200 in $1 \%$ BSA, $0.3 \%$ Triton in PBS) overnight at $4^{\circ} \mathrm{C}$. The following morning, after intense washing, the secondary antibody (anti-rabbit conjugated to Dylight 488) was added for 30 minutes. After washings with Tris-buffered saline containing $0.1 \%$ Tween-20 (TBST) 1X, slides were mounted in 4,6-diamidino-2-phenylindole (DAPI) and examined by fluorescence microscopy (Leica Microsystems, Wetzlar, Germany).

Cells grown on glass coverslips were fixed for 30 minute in paraformaldehyde $4 \%$ in PBS, washed, permeabilized with Triton $\times 100$ $(0.1 \%$ in PBS, $\mathrm{pH} 8.0)$, washed again, and blocked in BSA $1 \%$ for 1 hour. Incubation with primary and secondary antibodies was similar to the protocol used on tissue sections.

Reverse-Transcription PCR. RNA was extract with Trigent reagent (Biomatik Corporation). RNA purity and concentration were assessed with a Nanodrop spectrophotometer ND-1000 (ThermoFisher Scientific, Wilmington, DE). Primers were designed as follows: $\beta$-actin forward 5'-CAC CCG CGA GTA CAA CCT TC- 3 ' and reverse 5 '-CCC ATA CCC ACC ATC ACA CC-3'; and $\beta 3$-adrenoceptor forward $5^{\prime}$-TAG TCC TGG TGT GGA TCG TGT CCG C-3' and reverse 5 '-GCG ATG AAA ACT CCG CTG GGA ACT A-3'. The SensiFAST cDNA Synthesis Kit (Bioline, Taunton, MA) was used to synthesize cDNA, which was then amplified by PCR using the 2X Taq FroggaMix (FroggaBio, Toronto, ON, Canada). PCR products were resolved on a $1.2 \%$ agarose gel containing ethidium bromide and were photographed under UV light (Diehl et al., 2016). 
Quantitative Real-Time PCR. Primer sequences (IDT: Integrated DNA Technology, Skokie, IL) were designed as follows: rat GAPDH (forward 5' -TGC CAC TCA GAA GAC TGT GG-3'; reverse $5^{\prime}$-TTC AGC TCT GGG ATG ACC TT-3') and $\beta 3$-adrenoreceptor (forward 5'-CGT AAC CAC CAA CCC TCT GCG TTA-3'; reverse 5'-ACG ATC CAC ACC AGG ACT ACT GC-3'). Reverse transcription was performed using TranScript All-in-One First-Strand cDNA Synthesis Supermix for qPCR (One-Step gDNA Removal; TransGen Biotech, Montreal, Canada). The TransStart Tip SYBR Green qPCR Super Mixture (TransGen Biotech) was used for quantitative realtime polymerase chain reaction (qRT-PCR). Samples were placed in a 96 fast-PCR plate (Sarstedt, Montreal, Canada) and inserted in an 7500 Fast Real-time PCR System Applied Biosystems; Foster City, CA). Dissociation curves confirmed the specificity of the signals. Data were analyzed using the $\Delta \Delta$ CT method (Livak and Schmittgen, 2001).

Nitric Oxide Enzymatic Essay. Samples of media were analyzed for the amount of NO using a colorimetric method involving sulfanilamide/1-(naphthyl-ethylenediamine dihydrochloride (NEDD), as described elsewhere (Grisham et al., 1996).

Western Blotting. Cells were homogenized in RIPA buffer containing antiproteases (Roche Diagnostics, Indianapolis, IN). Proteins concentration in lysate was measured by Micro BCA assay kit (Boster Biological Technology), and equal amounts of protein $(20-40 \mu \mathrm{g})$ were loaded on $8 \%$ polyacrylamide gel and then electrotransferred to polyvinylidene difluoride membranes. After blocking in 5\% nonfat milk in TBST for 1 hour, overnight incubation with primary antibodies $\left(4^{\circ} \mathrm{C}\right)$ was performed in the following concentrations: 1:2000 for p-ERK, p-JNK, ERK. and JNK; 1:1000 for iNOS; 1:2000 for $\beta 3$-AR; and 1:10,000 for $\beta$-actin.

Secondary antibodies conjugated with horseradish peroxidase (HRP) were used the following day (anti-mouse or anti-rabbit at concentration 1:5000 in 5\% nonfat milk/TBST for 1 hour at room temperature), and bands were revealed using a Luminata Crescendo HRP substrate (Millipore, Billerica, MA) and quantified by ImageJ (open access software from the U.S. National Institutes of Health, Bethesda, MD).

For the relative protein quantification, $\beta$-actin was used as a reference "housekeeping" protein for $\beta 3$-AR and iNOS, and unphosphorylated ERK and JNK were used to quantify p-ERK and p-JNK, respectively. We selected $\beta$-actin as a housekeeping protein because it was not found to be affected by mirabegron treatment after 3 days in bladder tissue extracts (Imamura et al., 2017). We have also used $\beta$-actin as a reference protein for succinate as it did not change with succinate incubation (Mossa et al., 2017). Furthermore, in all blotting experiments $\beta$-actin was incubated with relevant antibodies and exposed independently. It did not show variation among samples in response to treatment conditions, when loading the same concentration of proteins led to equivalent $\beta$-actin band densities across different samples. Representative blots of the protein of interest and the reference protein are shown in the figures.

Statistical Analysis. The results are expressed as median and S.E.M. Statistical significance is expressed as $P<0.05,<0.01$, and $<0.001$. Comparisons were performed with independent Student's $t$ test and one-way analysis of variance (post hoc Tukey honestly significant difference test), as indicated in the figure legends. GraphPad software (San Diego, CA) was used for the statistical analyses.

\section{Results}

Characterization of the $\beta 3-A R$ in Cell Culture and Tissue Samples. We first confirmed $\beta 3$-AR receptor involvement in the mirabegron response via quantifying the receptor abundance by immunoblotting in cultured urothelial cells and SMC and cellular localization by immunohistochemistry in rat bladder tissue. Urothelial and SMC in culture express the mRNA for $\beta 3$-AR, as revealed by RT-PCR using $\beta$-actin as a control (Fig. 1A, left). Expression is statistically significantly higher in SMC as measured by qRT-PCR (Fig. 1A, right). Immunoblotting showed that SMC express twice the amount of receptor (Fig. 1B). Immunohistochemical analysis confirmed the expression in cell culture (Fig. 1C). On rat bladder sections, the receptor was found in the urothelium, connective tissue, and the SMC of the detrusor (Fig. 1D).

Mirabegron-Stimulated cAMP Synthesis. To determine how succinate influences cAMP production in both urothelial cells and SMC, mirabegron and forskolin-a receptor-independent stimulator of adenylate cyclase (Seamon et al., 1981)-were used to stimulate its levels. In urothelial cells (Fig. 2A) and SMC (Fig. 2B), forskolin (5 $\mu \mathrm{M})$ increased cAMP levels while succinate $(200 \mu \mathrm{M})$ abolished the increase. Mirabegron did not increase intracellular cAMP in urothelial cells (Fig. 2C), but it dose-dependently stimulated it in SMC (Fig. 2D). Mirabegron $(10 \mu \mathrm{M})$ incubated for 20 minutes led to an increase of cAMP levels in SMC that were inhibited by succinate preincubation for 30 minutes $\left(\mathrm{IC}_{50}=0.98 \mathrm{mM}\right)$ (Fig. 2E) or 24 hours (Fig. 2F), suggesting that succinate impairs cAMP-mediated bladder relaxation by mirabegron in vivo. No effect of mirabegron or preincubation with succinate could be seen in urothelial cells (Fig. 2E).

Nitric Oxide Secretion. We previously reported that succinate potently stimulates iNOS synthesis and NO secretion in SD rat urothelial cells (Mossa et al., 2017). To determine whether NO production participates in mirabegron relaxation, we demonstrated that both succinate and mirabegron increased iNOS synthesis and NO secretion only in urothelial cells, suggesting that its release indirectly induces SMC relaxation.

Urothelial cells and SMC were incubated with succinate $(200 \mu \mathrm{M})$ or mirabegron $(10 \mu \mathrm{M})$ or both products for 24 hours. Controls were carried out in parallel. In urothelial cells, NO levels and iNOS content were increased by succinate or mirabegron, with no additive or synergistic effects when combined; no change was observed in SMC (Fig. 3A). This suggests that NO release indirectly induces SMC relaxation.

Urothelial cells intracellular pathways involved in NO secretion were examined by using pertussis toxin (PTX) $(100 \mathrm{ng} / \mathrm{ml}$ for 18 hours), an inhibitor of protein $\mathrm{G}_{\mathrm{i}}$ (Moss et al., 1984), 2-(2amino-3-methoxyphenyl)chromen-4-one (PD98059) (10 $\mu \mathrm{M}$ for 30 minutes), inhibitor of MAPK (Alessi et al., 1995), and methyl (2S)-2-amino-5-[[amino(nitramido)methylidene]amino] pentanoate (L-NAME) (1 mM, for 30 minutes), a nonspecific inhibitor of NO synthase (Rees et al., 1990). Mirabegron stimulation of NO secretion was abolished by preincubation with PTX, PD98059, and L-NAME, demonstrating involvement of protein $\mathrm{G}_{\mathrm{i}}$, the MAPK pathway, and NO synthase (Fig. 3B). Forskolin ( $5 \mu \mathrm{M}$ for 20 minutes) by itself decreased NO production, suggesting that the presence of cAMP inhibits NO secretion (Fig. 3B). Succinate-stimulated NO secretion was sensitive to UBO ( $100 \mathrm{nM}$ for 30 minutes), an inhibitor of protein Gq (Gao and Jacobson, 2016), PD98059 (10 $\mu \mathrm{M})$, and L-NAME (1 mM), suggesting a potentially common pathway with mirabegron (Fig. 3B).

Activation of JNK and ERK Pathways. Succinate binds its receptor GPR91 on urothelial cells to activate many pathways, two of them being JNK and ERK (Mossa et al., 2017). Cells were incubated with succinate $(200 \mu \mathrm{M})$ or mirabegron $(10 \mu \mathrm{M})$ or both, for a short period (2 minutes for ERK phosphorylation, and 10 minutes for JNK phosphorylation). In urothelial cells, both compounds increased phosphorylation 
A

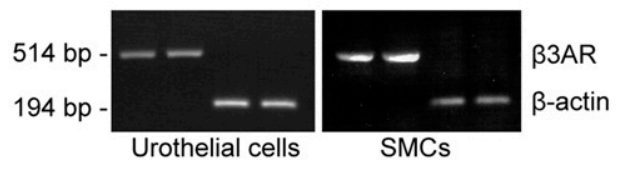

B

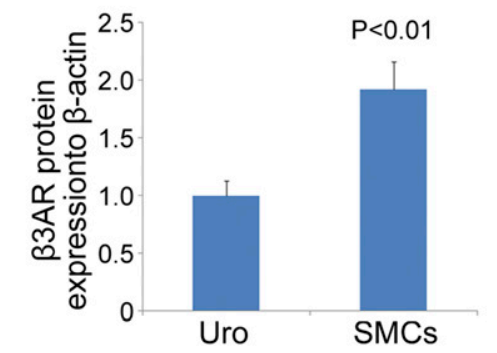

C

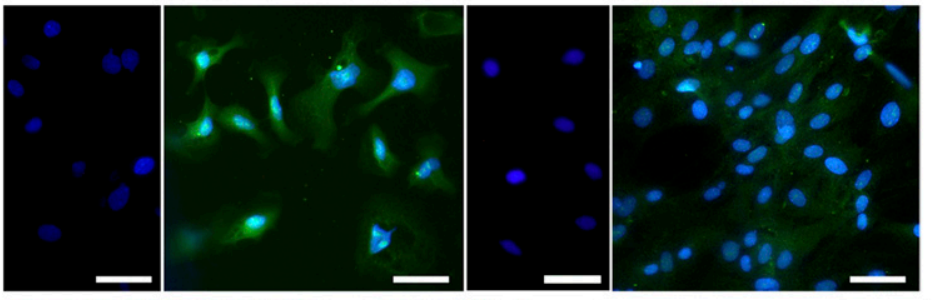

D

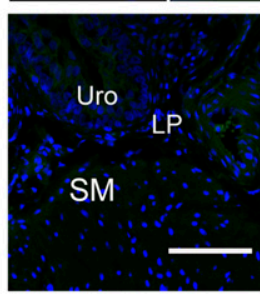

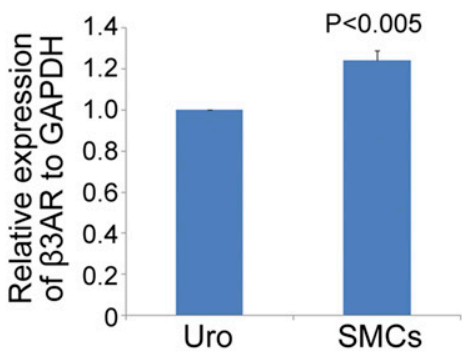
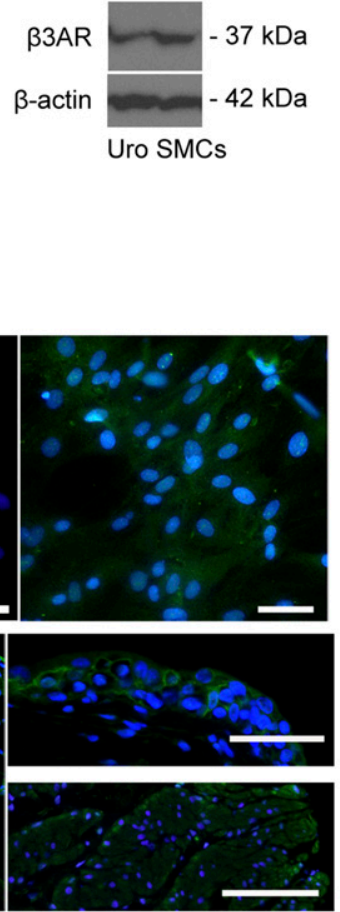

Fig. 1. Detection of $\beta 3-A R$ in cell culture and SD rat bladder. (A) RT-PCR revealed the presence of $\beta 3-\mathrm{AR}$ in culture of urothelial cells and SMC from SD rats ( $\beta$-actin was used as control). Quantitative PCR showed a higher expression of $\beta 3-\mathrm{AR}$ in SMC $(n=4$, two replicates) (Student's $t$ test, $P<0.005$ ). (B) Immunoblotting showed a higher amount of $\beta 3$-AR in SMC (Student's $t$ test, $P<0.01)(n=6$, two replicates). (C) Immunohistochemistry confirmed the presence of $\beta 3$-AR in cell culture. From left to right, negative control of urothelial cells, urothelial cells, negative control of SMC, SMC (scale bar: $50 \mu \mathrm{m}$ ). (D) In SD rat bladder sections, $\beta 3-\mathrm{AR}$ was expressed in different layers of the bladder wall. Left: Negative control without primary antibody (scale bar: $100 \mu \mathrm{m}$ ). Middle: Bladder section from SD rats with positive signal (green fluorescence) in urothelium (Uro), lamina propria (LP), and detrusor SMC (SM). Lumen at top of the section: Blue fluorescence for nuclei (4,6-diamidino2-phenylindole, DAPI) (scale bar: $100 \mu \mathrm{m}$ ). Top right: $\beta 3$-AR green florescence in urothelial layer (scale bar: $50 \mu \mathrm{m})$. Bottom right: $\beta 3-\mathrm{AR}$ green fluorescence in detrusor SMC (scale bar: $50 \mu \mathrm{m}$ ). of JNK and ERK, with no additional effect when combined $(n=5)$ (Fig. 4A). In SMC, only mirabegron stimulated JNK phosphorylation (Fig. 4B). No increase of P-ERK could be detected ( $n=5$ ) (Fig. 4B).

Succinate Inhibition of $\beta 3-A R$ Expression in Tissue and Cell Cultures. To determine whether the presence of succinate impacts the amount of bladder $\beta 3$-AR and potential downstream activity, we analyzed its expression using RT-PCR and immunoblotting in different conditions. In rats treated chronically for 4 weeks with a daily succinate intraperitoneal injection $\left(50 \mathrm{mg} / \mathrm{kg}^{-1}\right)$, protein levels of $\beta 3-\mathrm{AR}$ in whole bladder samples were decreased compared with salinetreated control animals; mRNA levels were unaffected (Fig. 5A). Exposure of SMC (Fig. 5B) to succinate $(200 \mu \mathrm{M})$ for 24 hours yielded similar results. On the other hand, succinate did not have any effect on the urothelial cell $\beta 3$-AR levels (Fig. $5 \mathrm{C}$ ). Decreased expression of $\beta 3$-adrenergic receptor protein in whole bladders in vivo and in SMC in vitro after exposure to succinate indicates that this metabolite may change mirabegron pharmacodynamics in the bladder.

\section{Discussion}

In this study, after confirming the expression of GPR91 and $\beta 3$-AR in the urothelial cells and SMC of SD rat bladders, we demonstrated that preincubation of SMC with succinate reduced cAMP production induced by mirabegron. Furthermore, succinate administration decreased the expression of $\beta 3$-AR in vivo and in SMC culture conditions. This effect can interfere with cAMP production; the main pharmacologically induced pathway by which mirabegron relaxes the bladder wall is through $\beta 3$-AR. Together, our results demonstrate that increased levels of succinate present in settings of metabolic stress (e.g., the metabolic syndrome), would affect mirabegron and $\beta 3$-AR pharmacodynamics at the bladder and prevent cAMP production, ultimately requiring mirabegron dose adjustment for the treatment of $\mathrm{OAB}$ related to these conditions.

We previously demonstrated the presence of the GPR91 receptor in urothelial cells and SMC from SD rat bladders (Mossa et al., 2017) and showed a higher expression of this receptor in urothelial cells. Here, RT-PCR, qRT-PCR, immunoblotting, and immunohistochemistry confirmed the presence of $\beta 3$-AR in culture of both cell types from SD rats, with higher expression of $\beta 3$-AR in SMC.

In bladder tissue, staining for the receptor was observed intensively in the urothelium and slightly fainter in the detrusor muscle, as previously reported by others, confirming the poor specificity of the antibody in immunofluorescence staining (Kullmann et al., 2011). The selectivity of mirabegron to $\beta 3$-AR in rat bladder was confirmed previously by other teams as shown 


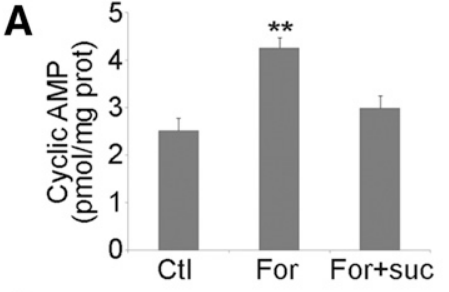

C
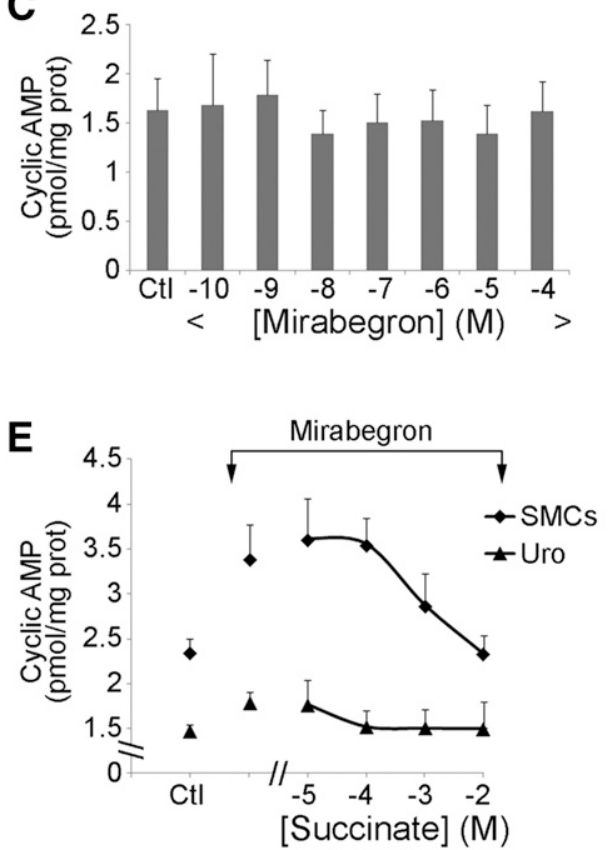

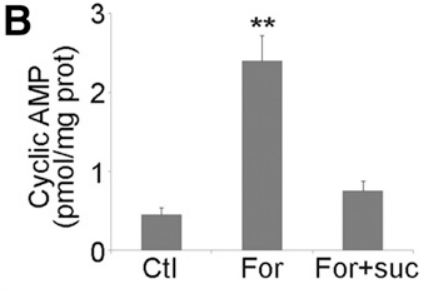

D 5

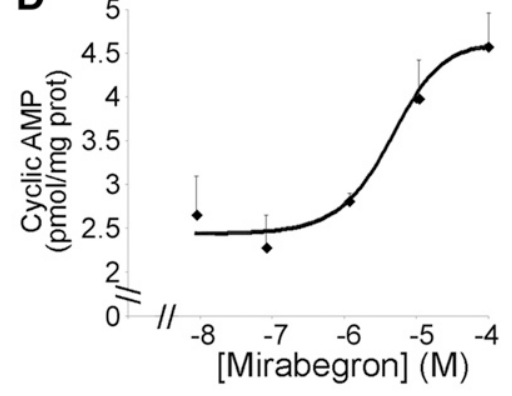

$\mathbf{F}$

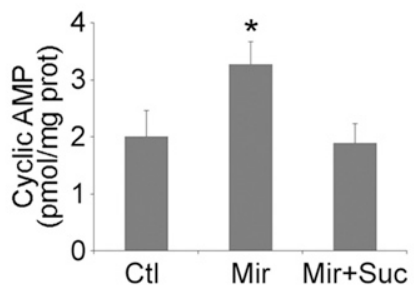

Fig. 2. Mirabegron and succinate effects on cAMP synthesis. In (A) urothelial cells and (B) SMC, forskolin $(10 \mu \mathrm{M})$ led to an increase in cAMP levels that was prevented by preincubation with succinate $(200 \mu \mathrm{M})$ ( $n=6$, two replicates) (one-way analysis of variance, ** $P<0.01$ compared with control). (C) $\beta 3$-AR agonist mirabegron did not change cAMP levels in urothelial cells ( $n=6$, four replicates). (D) In SMC, mirabegron dose-dependently increased cAMP levels $\left(\mathrm{EC}_{50}=\right.$ $4.83 \mu \mathrm{M})(n=6$, three replicates). (E) Succinate dosedependently decreased mirabegron-stimulated cAMP rise in $\mathrm{SMC}\left(\mathrm{IC}_{50}=0.98 \mathrm{mM}\right)(n=6$, four replicates $)$ but had no effect in urothelial cells. (F) SMC incubated for 24 hours with succinate $(200 \mu \mathrm{M})$ were unable to synthesize cAMP in the presence of mirabegron $(10 \mu \mathrm{M})(n=5$, two replicates) (one-way analysis of variance, $* P<0.05$ compared with control). by the dose-response relaxation curve of mirabegron on rat bladder strips. The relaxation curves were unaffected neither by high concentrations of the $\beta 1$-adrenoceptor selective antagonist CGP-20712A (2-hydroxy-5-[2-[[2-hydroxy-3-[4-[1-methyl-4(trifluoromethyl)imidazol-2-yl]phenoxy]propyl]amino]ethoxy]benzamide) nor by the $\beta 2$-adrenoceptor selective antagonist ICI-118,551 [(2R,3R)-1-[(7-methyl-2,3-dihydro- $1 H$-inden-4-yl)oxy]3-(propan-2-ylamino)butan-2-ol], demonstrating that mirabegron in rat bladder binds exclusively $\beta 3$-adrenoceptors (Hatanaka et al., 2013).

GPR91 and $\beta 3$-AR receptors are traditionally linked to protein $\mathrm{G}_{\mathrm{i}}$ and $\mathrm{G}_{\mathrm{s}}$, respectively. Forskolin, a receptor-independent stimulator of adenylate cyclase (Seamon et al., 1981), increased cAMP synthesis, demonstrating the ability of urothelial cells and SMC to synthesize cAMP. These increases were abolished by succinate in both short-term and long-term incubation, confirming the activation of protein $\mathrm{G}_{\mathrm{i}}$ by GPR91 in both cell types (Mossa et al., 2017).

On the other hand, mirabegron dose-dependently increased cAMP in SMC while there was no effect in urothelial cells, suggesting that $\beta 3-A R$ receptors are linked to protein $G_{\mathrm{s}}$ in SMC but not in urothelial cells. The absence of cAMP secretion in response to mirabegron in urothelial cells could be related to its stimulation of $\alpha 2$-adrenergic receptors (Michel, 2016), highly expressed in urothelial cells (Michel and Vrydag, 2006), which can decrease cAMP production (Weiss et al., 1987; Hancock et al., 1995). However, in some tissues, $\beta 3$-AR signals through the $\mathrm{G}_{\mathrm{i}}$ pathway. In adipocytes for example, $\beta 3$-AR agonist activates ERK1 and ERK2 by the stimulation of protein $\mathrm{G}_{\mathrm{i}}$ (Gerhardt et al., 1999; Soeder et al., 1999). In the heart, $\beta 3$-agonists possess negative inotropic effects by stimulating protein $\mathrm{G}_{\mathrm{i}}$ as well (Gauthier et al., 1996).

Notably, mirabegron-stimulated increase in cAMP in SMC were dose-dependently inhibited by succinate, but with no effect in urothelial cells. The $\mathrm{IC}_{50}$ of succinate $(0.98 \mathrm{mM})$ was in the range of the pathophysiologic concentrations encountered in metabolic diseases (Sadagopan et al., 2007; Toma et al., 2008) or cancer (Sullivan et al., 2016). Therefore, incremental dose adjustments of mirabegron may be required for adequate efficacy of OAB treatment in these conditions.

Mirabegron is approved for the treatment of $\mathrm{OAB}$ in approximately 50 countries worldwide. In North America, the initial dosing recommended is $25 \mathrm{mg}$ daily, with an increase to $50 \mathrm{mg}$ daily based on individual patient efficacy and tolerability, with adequate renal and hepatic function.

NO secretion and iNOS expression were increased in urothelial cells by succinate and mirabegron, but no stimulation could be detected in SMC. No synergistic or additive effect could be seen, suggesting a common pathway of action. $\beta 3$-AR receptors have been reported to increase activity of $\mathrm{NO}$ synthases, increasing NO release, in urothelial cells (Birder et al., 2002) and in the cardiovascular system (Moens et al., 2010), among other tissues. In urothelial cells, increase in NO release by mirabegron results from recruitment of protein $G_{i}$ by $\beta 3-\mathrm{AR}$ receptors (Gerthoffer, 2005; Li et al., 2007) and requires activation of ERK/MAPK pathways (Gerhardt et al., 1999; Gerthoffer, 2005; Li et al., 2007) that in turn activate iNOS synthesis (Xu et al., 2006). This recruitment of protein 

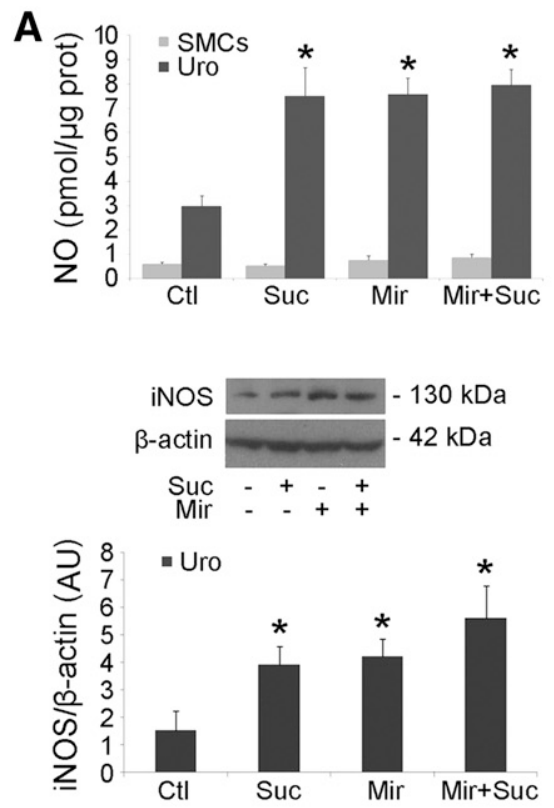

B
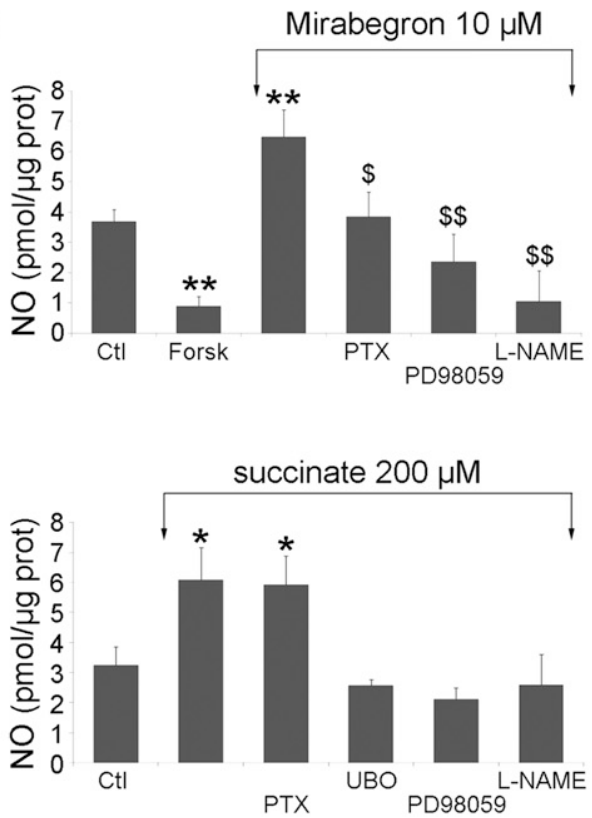

Fig. 3. Secretion of NO in cell cultures. (A) Succinate $(200 \mu \mathrm{M})$ or mirabegron $(10 \mu \mathrm{M})$ incubated with urothelial cells for 24 hours increases secretion of NO detected in culture medium and synthesis of iNOS detected by Western blotting. In SMC, no stimulation was observed in NO secretion. ( $n=6$, three replicates). One-way analysis of variance, ${ }^{*} P<0.05$ compared with controls (Ctl). (B) In urothelial cells, mirabegron-stimulated increase of NO was abolished by preincubation with PTX for 18 hours $(100 \mathrm{ng} / \mathrm{ml})$, PD98059 for 30 minutes $(10 \mu \mathrm{M})$, or L-NAME for 30 minutes $(1 \mathrm{mM})$. Forskolin alone ( $5 \mu \mathrm{M}$ for 20 minutes) decreased basal levels of nitric oxide. Succinate-stimulated secretion of NO in urothelial cells was completely inhibited by UBO for 30 minutes $(100 \mathrm{nM})$, PD98059 $(10 \mu \mathrm{M})$, or L-NAME $(1 \mathrm{mM})$ but was unaffected by PTX $(100 \mathrm{ng} / \mathrm{ml})(n=6$, three replicates). One-way analysis of variance, $* * P<0.01 ; * P<0.05$ compared with controls (Ctl); ${ }^{\$} P<0.01 ;{ }^{\$} P<0.05$ compared with mirabegron alone.

$\mathrm{G}_{\mathrm{i}}$ by $\beta 3-\mathrm{AR}$ receptors goes along well with lack of cAMP increase by mirabegron in urothelial cells. On the other hand, succinate receptor joins up with MAPK pathway in a protein $\mathrm{G}_{\mathrm{i}}$-independent fashion but protein $\mathrm{G}_{\mathrm{q}}$-dependent way. Both compounds are sensitive to L-NAME, confirming the involvement of NO synthase enzymes.
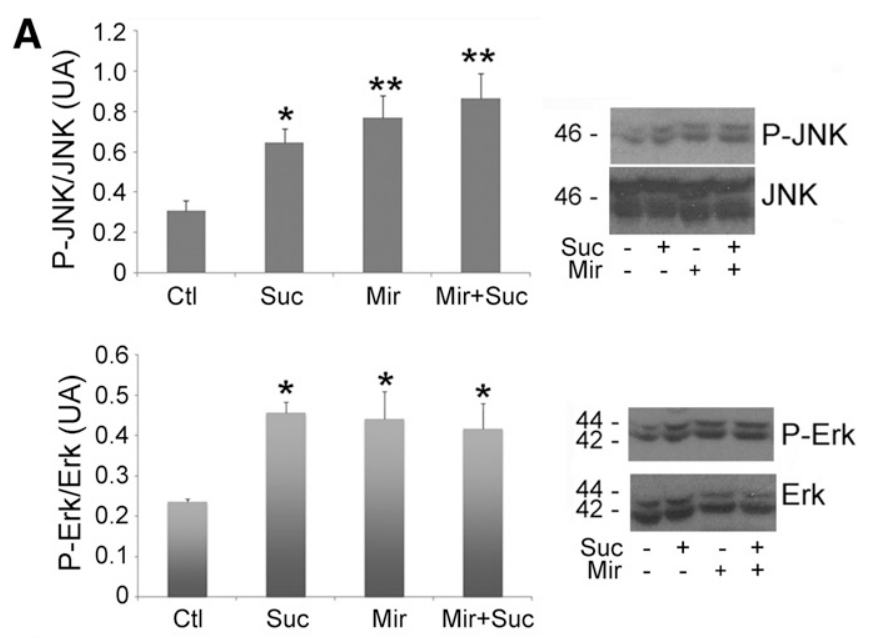

B
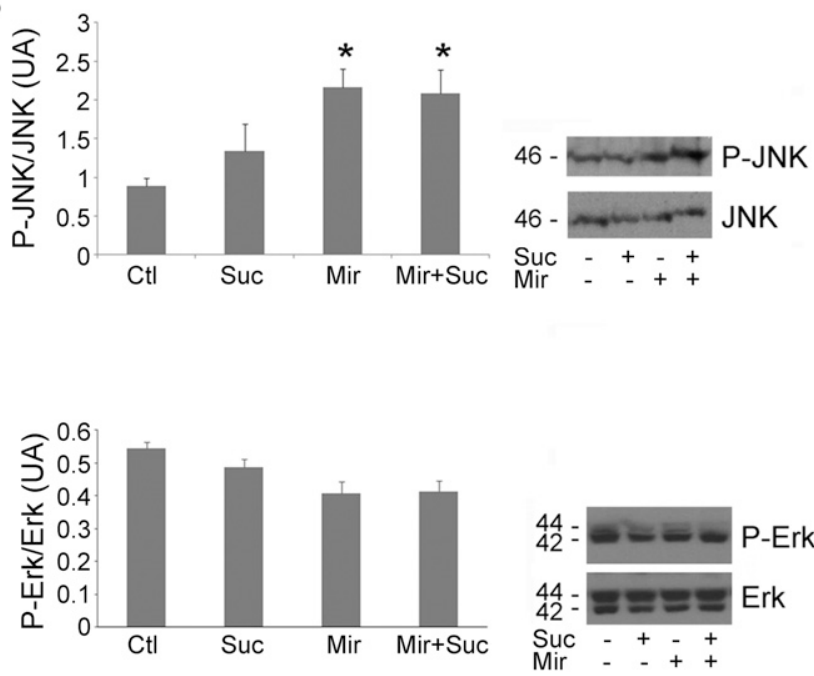

Fig. 4. Activation of ERK and JNK pathways in urothelial cells and SMC by succinate and mirabegron. (A) Urothelial cells were incubated with succinate $(200 \mu \mathrm{M})$ or mirabegron $(10 \mu \mathrm{M})$ or both. Succinate and mirabegron increased phosphorylation of JNK (after 10 minutes) and ERK (after 2 minutes), with no additional effect when combined ( $n=5$, two replicates). (B) In SMC, mirabegron stimulated JNK phosphorylation (B). No increase of P-ERK could be detected in either cell type $(n=5$, two replicates) (B). One-way analysis of variance, ${ }^{*} P<0.01 ; * P<0.05$, compared with controls (Ctl).

Finally, forskolin per se inhibits NO synthesis in the urothelial cells while it increases cAMP release. This suggests that NO synthesis by urothelial cells, as demonstrated in the $\beta-$ cells of the pancreas and glial cells, is affected by cAMP levels where NO synthase expression and NO synthesis are decreased by high cAMP levels (Beshay and Prud'homme, 2001; Won et al., 2001).

ERK and JNK are essential in the control of stress, inflammation, cell growth, and apoptosis by cells (Tawadros et al., 2002; Swiatkowski et al., 2003). In the case of the bladder, an increase in bladder pressure (an increase in mechanical stress) increases phosphorylation of JNK, in particular in the urothelium in vivo (Tawadros et al., 2002) and in SMC in vitro (Kushida et al., 2001). Similarly, elevated intravesical pressure activates ERK in the urothelium but not in the detrusor muscle (Sano et al., 2016). It is well established that $\beta 3$-AR receptors stimulate phosphorylation of ERK proteins in a cAMP/adenylate cyclase-independent way, but in a protein $\mathrm{G}_{\mathrm{i}} / \mathrm{ERK}$ or PI3K/MAPK pathway (Gerhardt et al., 1999; 
A

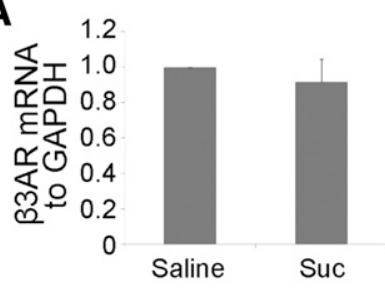

B

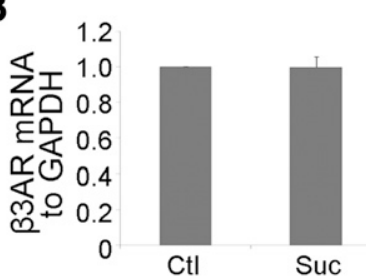

C

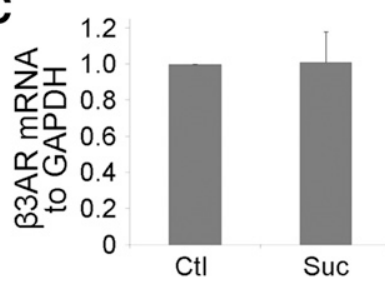

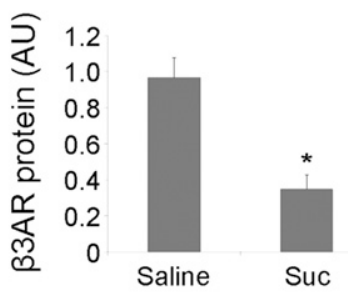

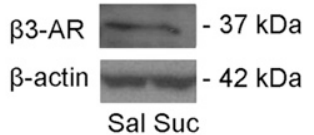

Sal Suc
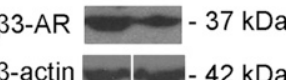

Ctl Suc
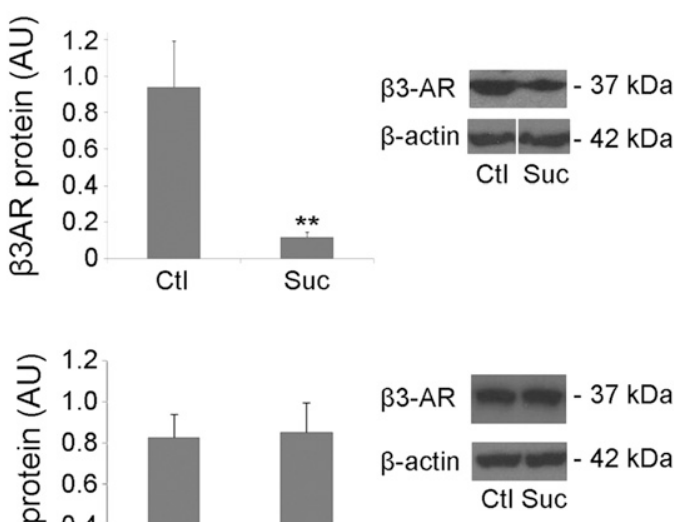

Fig. 5. Decrease of $\beta 3$-receptors synthesis by succinate. (A) Rats injected daily for 4 weeks with succinate (Suc) $(50 \mathrm{mg} / \mathrm{kg}$ per day) intraperitoneally displayed a decrease in the levels of $\beta 3$-AR protein of whole bladder samples compared with saline-injected controls as detected by Western blotting; $\beta 3$-AR mRNA levels were unchanged ( $n=6$, two replicates). (B) SMC isolated from SD rats and incubated for 24 hours with succinate $(200 \mu \mathrm{M})$ displayed similar results ( $n=6$, two replicates). (C) Urothelial cells were not affected ( $n=6$, two replicates). Student's $t$ test, ${ }^{*} P<0.05$.
Soeder et al., 1999; Hutchinson et al., 2002). The classic p38/PKC pathway is also required by GPR91 in urothelial cells (Mossa et al., 2017) and in other cell types (Tchivileva et al., 2009), confirming that our findings are in line with the literature. Succinate via GPR91 receptor and mirabegron via $\beta 3$-AR activation may participate in the adaptation of the bladder during mechanical stress.

$\beta 3$-AR receptor mRNA was unaffected by succinate both in vivo and in vitro. On the other hand, the density of the receptor itself at the protein level was decreased in rats after 4-weeks of exposure to succinate as well as in SMC in culture after 24 hours of incubation with pathophysiologic concentrations of succinate. During hypoxia and in metabolic diseases such as diabetes, succinate levels are elevated (Rohrmann et al., 2005; He et al., 2016). In Wistar rats, exposure to hypoxic environment for several days decreases the density of $\beta$-adrenergic receptors in the heart (Mardon et al., 1998) and lungs (Shaul et al., 1990). In diabetes, the amount of $\beta 3$-AR in the prostate and heart decreases dramatically (Gousse et al., 1991; Haley et al., 2015).

Our results are in accordance with studies reporting pathologic states linked to high systemic succinate levels that are linked with a decreased expression of $\beta 3$-AR. The lower expression of $\beta 3$-AR in the detrusor in these conditions specifically may affect the pharmacodynamics of $\beta 3$-agonists such as mirabegron on bladder relaxation. The down-regulation of $\beta 3-\mathrm{AR}$ in the bladder with chronic exposure to succinate could explain the smaller bladder capacity in SD rats injected chronically with succinate in our previous study (Velasquez Flores et al., 2018). In addition to the structural changes we observed, such as increased collagen density and an altered nerve profile, the low expression of $\beta 3$-AR in these bladders might reduce adrenergicdependent bladder relaxation and further worsen the bladder capacity.
Our findings do not provide a clear explanation for the decreased expression of $\beta 3-A R$ protein, despite the unchanged $\beta 3$-AR mRNA. Further studies are needed to understand the posttranslational modification, enhanced internalization, or degradation of this receptor in response to metabolic diseases. Colocalization of the GPR91 and $\beta 3$-AR receptors in cell culture and bladder sections would also help to identify the proportional expression of each receptor in response to succinate exposure. Our lack of a specific GPR91 antibody to GPR91 prevents us from clarifying this question. Furthermore, clinical trials studies on mirabegron efficacy in the specific patient population with $\mathrm{OAB}$ with details about the patients' metabolic profiles are lacking.

Taken together, our results show that pathophysiologic concentrations of succinate share common pathways with mirabegron in bladder cell signaling. However, high concentrations of succinate might blunt the effects of mirabegron on the detrusor by diminishing the ability of $\beta 3$-AR to activate the synthesis of cAMP and, in the long term, by decreasing the density of the $\beta 3$-AR. This pharmacometabolomic interaction should be taken into account to guide drug selection and drug dosing for $\mathrm{OAB}$ treatment in patients with pathologies linked to high systemic levels of succinate.

\section{Authorship Contributions}

Participated in research design: Mossa, Velasquez Flores, Nguyen, Cammisotto, Campeau.

Conducted experiments: Mossa, Velasquez Flores, Nguyen, Cammisotto.

Performed data analysis: Mossa, Velasquez Flores, Nguyen, Cammisotto, Campeau.

Wrote or contributed to the writing of the manuscript: Mossa, Velasquez Flores, Nguyen, Cammisotto, Campeau.

\section{References}

Abrams P (2003) Describing bladder storage function: overactive bladder syndrome and detrusor overactivity. Urology 62(5 Suppl 2):28-37, discussion 40-42. 
Abrams P and Andersson KE (2007) Muscarinic receptor antagonists for overactive bladder. BJU Int 100:987-1006.

Alessi DR, Cuenda A, Cohen P, Dudley DT, and Saltiel AR (1995) PD 098059 is a specific inhibitor of the activation of mitogen-activated protein kinase kinase in vitro and in vivo. $J$ Biol Chem 270:27489-27494

Beshay E and Prud'homme GJ (2001) Inhibitors of phosphodiesterase isoforms III or IV suppress islet-cell nitric oxide production. Lab Invest 81:1109-1117.

Birder LA, Nealen ML, Kiss S, de Groat WC, Caterina MJ, Wang E, Apodaca G, and Kanai AJ (2002) $\beta$-adrenoceptor agonists stimulate endothelial nitric oxide synthase in rat urinary bladder urothelial cells. J Neurosci 22:8063-8070.

Corcos J, Przydacz M, Campeau L, Gray G, Hickling D, Honeine C, Radomski SB, Stothers L, Wagg A, and Lond F (2017) CUA guideline on adult overactive bladder. Can Urol Assoc J 11:E142-E173.

Diehl J, Gries B, Pfeil U, Goldenberg A, Mermer P, Kummer W, and Paddenberg R (2016) Expression and localization of GPR91 and GPR99 in murine organs. Cell Tissue Res 364:245-262.

Gao Z-G and Jacobson KA (2016) On the selectivity of the G $\alpha$ q inhibitor UBO-QIC: a comparison with the G $\alpha$ i inhibitor pertussis toxin. Biochem Pharmacol 107:59-66.

Gauthier C, Tavernier G, Charpentier F, Langin D, and Le Marec H (1996) Functional $\beta 3$-adrenoceptor in the human heart. J Clin Invest 98:556-562.

Gerhardt CC, Gros J, Strosberg AD, and Issad T (1999) Stimulation of the extracellular signal-regulated kinase 1/2 pathway by human beta-3 adrenergic receptor: new pharmacological profile and mechanism of activation. Mol Pharmacol 55:255-262.

Gerthoffer WT (2005) Signal-transduction pathways that regulate visceral smooth muscle function. III. Coupling of muscarinic receptors to signaling kinases and effector proteins in gastrointestinal smooth muscles. Am J Physiol Gastrointest Liver Physiol 288:G849-G853.

Gormley EA, Lightner DJ, Faraday M, and Vasavada SP; American Urological Association; Society of Urodynamics, Female Pelvic Medicine (2015) Diagnosis and treatment of overactive bladder (non-neurogenic) in adults: AUA/SUFU guideline amendment. J Urol 193:1572-1580.

Gousse A, Yoshida M, Weiss RM, and Latifpour J (1991) Beta adrenergic receptor alterations in diabetic rat prostate: effects of insulin and dietary myoinositol. Prostate 19:121-131.

Grisham MB, Johnson GG, and Lancaster JR, Jr (1996) Quantitation of nitrate and nitrite in extracellular fluids. Methods Enzymol 268:237-246.

Haley JM, Thackeray JT, Thorn SL, and DaSilva JN (2015) Cardiac $\beta$-adrenoceptor expression is reduced in Zucker diabetic fatty rats as type-2 diabetes progresses. PLoS One 10:e127581.

Hancock AA, Vodenlich AD, Maldonado C, and Janis R (1995) $\alpha 2$-Adrenergic agonistinduced inhibition of cyclic AMP formation in transfected cell lines using a microtiterbased scintillation proximity assay. J Recept Signal Transduct Res 15:557-579.

Hatanaka T, Ukai M, Watanabe M, Someya A, Ohtake A, Suzuki M, Ueshima K, Sato S, and Sasamata M (2013) In vitro and in vivo pharmacological profile of the selective $\beta 3$-adrenoceptor agonist mirabegron in rats. Naunyn Schmiedebergs Arch Pharmacol 386:247-253.

He Q, Wang Z, Liu G, Daneshgari F, MacLennan GT, and Gupta S (2016) Metabolic syndrome, inflammation and lower urinary tract symptoms: possible translational links. Prostate Cancer Prostatic Dis 19:7-13.

He W, Miao FJ-P, Lin DC-H, Schwandner RT, Wang Z, Gao J, Chen J-L, Tian H and Ling L (2004) Citric acid cycle intermediates as ligands for orphan G-proteincoupled receptors. Nature 429:188-193.

Hutchinson DS, Bengtsson T, Evans BA, and Summers RJ (2002) Mouse $\beta 3 \mathrm{a}-$ and $\beta 3 \mathrm{~b}$ adrenoceptors expressed in Chinese hamster ovary cells display identical pharmacology but utilize distinct signalling pathways. Br J Pharmacol 135:1903-1914.

Imamura T, Ogawa T, Minagawa T, Nagai T, Suzuki T, Saito T, Yokoyama H, Nakazawa M, and Ishizuka O (2017) Combined treatment with a $\beta_{3}$-adrenergic receptor agonist and a muscarinic receptor antagonist inhibits detrusor overactivity induced by cold stress in spontaneously hypertensive rats. Neurourol Urodyn 36:1026-1033.

Kaddurah-Daouk R and Weinshilboum R; Pharmacometabolomics Research Network (2015) Metabolomic signatures for drug response phenotypes: pharmacometabolomics enables precision medicine. Clin Pharmacol Ther 98:71-75.

Kantae V, Krekels EHJ, Esdonk MJV, Lindenburg P, Harms AC, Knibbe CAJ, Van der Graaf PH, and Hankemeier T (2017) Integration of pharmacometabolomics with pharmacokinetics and pharmacodynamics: towards personalized drug therapy. Metabolomics 13:9.

Kullmann FA, Downs TR, Artim DE, Limberg BJ, Shah M, Contract D, de Groat WC and Rosenbaum JS (2011) Urothelial beta-3 adrenergic receptors in the rat bladder. Neurourol Urodyn 30:144-150.

Kushida N, Kabuyama Y, Yamaguchi O, and Homma Y (2001) Essential role for extracellular $\mathrm{Ca}(2+)$ in JNK activation by mechanical stretch in bladder smooth muscle cells. Am J Physiol Cell Physiol 281:C1165-C1172.

Li J, Zhao X, Li X, Lerea KM, and Olson SC (2007) Angiotensin II type 2 receptordependent increases in nitric oxide synthase expression in the pulmonary endothelium is mediated via a G $\alpha$ i3/Ras/Raf/MAPK pathway. Am $J$ Physiol Cell Physiol 292:C2185-C2196.

Li YH, Choi DH, Lee EH, Seo SR, Lee S, and Cho E-H (2016) Sirtuin 3 (SIRT3) regulates $\alpha$-smooth muscle actin ( $\alpha$-SMA) production through the succinate dehydrogenase-G protein-coupled receptor 91 (GPR91) pathway in hepatic stellate cells. $J$ Biol Chem 291:10277-10292.

Livak KJ and Schmittgen TD (2001) Analysis of relative gene expression data using real-time quantitative PCR and the $2(-\Delta \Delta \mathrm{C}(\mathrm{T}))$ method. Methods 25:402-408.

Mardon K, Merlet P, Syrota A, and Mazière B (1998) Effects of 5-day hypoxia on cardiac adrenergic neurotransmission in rats. J Appl Physiol (1985) 85: $890-897$
Michel MC (2016) How $\beta 3$-adrenoceptor-selective is mirabegron? Br J Pharmacol 173:429-430.

Michel MC and Vrydag W (2006) Alpha1-, alpha2- and beta-adrenoceptors in the urinary bladder, urethra and prostate. Br J Pharmacol 147:S88-S119.

Moens AL, Yang R, Watts VL, and Barouch LA (2010) Beta 3-adrenoreceptor regulation of nitric oxide in the cardiovascular system. $J$ Mol Cell Cardiol 48: 1088-1095.

Moss J, Bruni P, Hsia JA, Tsai S-C, Watkins PA, Halpern JL, Burns DL, Kanaho Y, Chang PP, Hewlett EL, et al. (1984) Pertussis toxin-catalyzed ADPribosylation: effects on the coupling of inhibitory receptors to the adenylate cyclase system. $J$ Recept Res 4:459-474.

Mossa AH, Velasquez Flores M, Cammisotto PG, and Campeau L (2017) Succinate, increased in metabolic syndrome, activates GPR91 receptor signaling in urothelial cells. Cell Signal 37:31-39.

Nitti VW, Auerbach S, Martin N, Calhoun A, Lee M, and Herschorn S (2013) Results of a randomized phase III trial of mirabegron in patients with overactive bladder. J Urol 189:1388-1395.

Rees DD, Palmer RM, Schulz R, Hodson HF, and Moncada S (1990) Characterization of three inhibitors of endothelial nitric oxide synthase in vitro and in vivo. Br J Pharmacol 101:746-752.

Rohrmann S, Smit E, Giovannucci E, and Platz EA (2005) Association between markers of the metabolic syndrome and lower urinary tract symptoms in the Third National Health and Nutrition Examination Survey (NHANES III). Int J Obes 29 310-316.

Sadagopan N, Li W, Roberds SL, Major T, Preston GM, Yu Y, and Tones MA (2007) Circulating succinate is elevated in rodent models of hypertension and metabolic disease. Am J Hypertens 20:1209-1215.

Sadananda P, Drake MJ, Paton JF, and Pickering AE (2013) A functional analysis of the influence of $\beta 3$-adrenoceptors on the rat micturition cycle. $J$ Pharmacol Exp Ther 347:506-515.

Sano T, Kobayashi T, Negoro H, Sengiku A, Hiratsuka T, Kamioka Y, Liou LS, Ogawa $\mathrm{O}$, and Matsuda M (2016) Intravital imaging of mouse urothelium reveals activation of extracellular signal-regulated kinase by stretch-induced intravesica release of ATP. Physiol Rep 4:e13033.

Seamon KB, Padgett W, and Daly JW (1981) Forskolin: unique diterpene activator of adenylate cyclase in membranes and in intact cells. Proc Natl Acad Sci USA 78: 3363-3367.

Shaul PW, Muntz KH, DeBeltz D, and Buja LM (1990) Effects of prolonged hypoxia on adenylate cyclase activity and beta-adrenergic receptors in pulmonary and systemic arteries of the rat. Circ Res 66:1526-1534.

Soeder KJ, Snedden SK, Cao W, Della Rocca GJ, Daniel KW, Luttrell LM, and Collins S (1999) The $\beta 3$-adrenergic receptor activates mitogen-activated protein kinase in adipocytes through a Gi-dependent mechanism. J Biol Chem 274: 12017-12022.

Sullivan LB, Gui DY, and Heiden MGV (2016) Altered metabolite levels in cancer: implications for tumour biology and cancer therapy. Nat Rev Cancer 16:680-693.

Sun J, Beger RD, and Schnackenberg LK (2013) Metabolomics as a tool for personalizing medicine: 2012 update. Per Med 10:149-161.

Swiatkowski S, Seifert H-H, Steinhoff C, Prior A, Thievessen I, Schliess F, and Schulz WA (2003) Activities of MAP-kinase pathways in normal uroepithelia cells and urothelial carcinoma cell lines. Exp Cell Res 282:48-57.

Tawadros T, Formenton A, Dudler J, Thompson N, Nicod P, Leisinger H-J, Waeber G, and Haefliger J-A (2002) The scaffold protein IB1/JIP-1 controls the activation of JNK in rat stressed urothelium. J Cell Sci 115:385-393.

Tchivileva IE, Tan KS, Gambarian M, Nackley AG, Medvedev AV, Romanov S, Flood PM, Maixner W, Makarov SS, and Diatchenko L (2009) Signaling pathways mediating $\beta 3$-adrenergic receptor-induced production of interleukin- 6 in adipocytes. Mol Immunol 46:2256-2266.

Toma I, Kang JJ, Sipos A, Vargas S, Bansal E, Hanner F, Meer E, and Peti-Peterdi J (2008) Succinate receptor GPR91 provides a direct link between high glucose levels and renin release in murine and rabbit kidney. $J$ Clin Invest 118:2526-2534.

Trupp M, Zhu H, Wikoff WR, Baillie RA, Zeng Z-B, Karp PD, Fiehn O, Krauss RM, and Kaddurah-Daouk R (2012) Metabolomics reveals amino acids contribute to variation in response to simvastatin treatment. PLoS One 7:e38386.

Vargas SL, Toma I, Kang JJ, Meer EJ, and Peti-Peterdi J (2009) Activation of the succinate receptor GPR91 in macula densa cells causes renin release. J Am Soc Nephrol 20:1002-1011.

Velasquez Flores M, Mossa AH, Cammisotto P, and Campeau L (2018) Succinate decreases bladder function in a rat model associated with metabolic syndrome. Neurourol Urodyn DOI: 10.1002/nau.23488 [published ahead of print].

Weiss S, Kemp DE, Lenox RH, and Ellis J (1987) $\alpha 2$-adrenergic receptors mediate inhibition of cyclic AMP production in neurons in primary culture. Brain Res 414: 390-394

Won J-S, Lee J-K, and Suh H-W (2001) Forskolin inhibits expression of inducible nitric oxide synthase mRNA via inhibiting the mitogen activated protein kinase in C6 cells. Brain Res Mol Brain Res 89:1-10.

Xu Z, Wang B-R, Wang X, Kuang F, Duan X-L, Jiao X-Y, and Ju G (2006) ERK1/2 and p38 mitogen-activated protein kinase mediate iNOS-induced spinal neuron degeneration after acute traumatic spinal cord injury. Life Sci 79:1895-1905.

Yamaguchi O and Chapple CR (2007) Beta3-adrenoceptors in urinary bladder. Neurourol Urodyn 26:752-756.

Address correspondence to: Dr. Lysanne Campeau, Lady Davis Research Institute, McGill University, 3755, Chemin de la cote-Ste-Catherine, Montreal, QC H3T 1E2, Canada. E-mail: lysanne.campeau@mcgill.ca 